manufacturing efficiency at Amersham. The saving to the average isotope user will be about 20 per cent. Both these isotopes are in ample supply. Although they are short lived-iodine loses half its activity in eight days and the gold loses half its activity in three days-they can be delivered by air to any part of the world at short notice; the Radiochernical Centre provides sufficient activity to compensate for that loss during transit. Among the more distant countries already using this service are Australia, New Zealand, Argentine, Uruguay, South Africa and Japan. The new prices are : iodine-131, in carrier-free solutiona minimum charge of $£ 1$ for 1 millicurie and $3 s .6 d$. per millicurie thereafter; iodine-131 in sterile solution-a minimum charge of $£ 2$ for 1 millicurie and $3 s .6 d$. per millicurie thereafter ; gold-198, in a colloidal solution-a minimum charge of $£ 5$ for 50 millicuries and $6 d$. per millicurie thereafter.

Academy of Zoology, India, and Annals of Zoology

IN 1954 a new society, the Academy of Zoology, was founded in India, with headquarters in Agra, under the presidency of Prof. B. C. Mahendra. Its aims are to further all branches of zoology and to encourage research, not only in India, but in countries in the East in general, with as international an appeal as possible. This is indeed an ambitious project. The Academy has started a new journal, the Annals of Zoology, each part of which will in general consist of a single memoir; supplements containing short notes, reviews, etc., will be issued from time to time, and special volumes may also be issued. The first part, which appeared in January this year $(1$, No. 1 (1955); pp. 22 ; Rs. 15 or $30 s$. for each volume of approximately $240 \mathrm{pp}$.), is a paper by Surendra Sharmer and P. N. Tiku on the venous system of Rana tigrina Daud, a frog widely used in the universities of northern India, for which no detailed account of the veins is available. The paper is a straightforward piece of work carefully done and based upon the classical account in Gaupp's "Anatomie des Froches", which is a good model. The authors have followed Gaupp in his incorrect account of the interpretation of the relationship of the abdominal vein and hepatic portal vein. The block-making and printing are well done upon good paper, and the text is remarkably free from errors. The editor, authors and printers are to be congratulated on a satisfactory production. Inside the cover, it is stated that the Academy intends to continue the well-known series of "Indian Zoological Memoirs" established by the late Prof. K. N. Bahl, which have come to an end with his much regretted death. This would be a valuable service to zoology and to Indian zoology in particular. Information regarding the Academy and the Annals can be obtained from the Secretary, Academy of Zoology, 164 Civil Lines, Agra.

\section{Air Pollution in Britain}

THE Clean Air Bill published on July 27 is intended to implement the principal recommendations of the report of the Beaver Committee on air pollution in Britain (London: H.M.S.O. 1s. net). It applies to Great Britain only, and four of its clauses prohibit the emission of dark smoke from chimneys, railway engines and vessels, subject to exemption by the Minister for specified periods to cover soot-blowing, the raking of boiler fires and other necessary operations which unavoidably cause smoke for a few minutes. It will be a defence to prove that emission of dark smoke was due solely to the lighting up of a furnace from cold, an unpreventable mechanical failure, the impracticability of obtaining suitable fuel, or (for the first seven years only) the unsatisfactory nature of the furnace and the impracticability of modifying it at reasonable cost. Clause 3 prohibits the installation of new industrial furnaces unless they are capable, so far as practicable, of being operated continuously without emitting smoke. Clauses 4-7 require the emission of grit and dust from existing industrial furnaces to be minimized, and new furnaces burning pulverized coal or large amounts of other solid fuel to be provided with grit-arresting equipment. Clause 8 empowers local authorities by Order (subject to confirmation by the Minister) to designate 'smoke-control areas' in which the emission of smoke from any chimney will constitute an offence. In such areas, grants covering at least 70 per cent of the cost of adapting or replacing grates and stoves to enable smokeless fuel to be used will be payable to owners or occupiers of private dwellings, of which 40 per cent will be paid by the Government and at least 30 per cent by the local authority. The cost of these clauses to the Exchequer is not expected to exceed $£ 3$ million a year, but expenditure up to $£ 40,000$ will be incurred by the appointment of additional staff by the Ministry of Housing and Local Government and the Department of Health for Scotland.

\section{Forestry in Malaya}

Is spite of all the troubles in Malaya, which must have made forestry working exceptionally difficult during the past few years, the Malayan Forester (17, No. 1; January 1955) maintains its high character. The number includes several papers presented to the Fourth World Forestry Congress held last December in Dehra Dun, India. One, on Malayan tropical rain forest, by F. H. Landon, is of exceptional interest. An important note is struck in the editorial on the housing question, which is as vital in many parts of Malaya as in Britain. In the past, the houses were built mainly of unseasoned timber and classified as 'temporary' or 'semi-permanent'. Only unseasoned wood was obtainable, and the timber trade made no effort to provide the public with seasoned wood. Now houses are built of brick and cement, tiles and metal windows, though there is an abundance of timber in the forests of the country which only requires the introduction of modern methods of seasoning to make available houses at a cheaper rate. It is scarcely a matter for surprise, then, that the Government is losing money on its forestry working.

\section{Evidence of Translocated Antibiotics in Expressed Plant Sap}

Detalls have been given by S. H. Crowdy and D. Pramer (Ann. Bot., N.S., 19, 79; 1955) of $a_{0}$ convenient and efficient press for extracting laboratory samples of plant sap. The pressing procedure is stated to release 53-74 per cent of the total water as expressed sap. They have also described briefly some preliminary experiments on the uptake and translocation of antibiotics. They have shown that the assay of expressed sap provides a measure of the griseofulvin and chloramphenicol concentrations in leaves of plants grown in solutions of these antibiotics, that is, in good agreement with the values obtained by the assay of water extracts. By using organic solvents, however, the authors have extracted considerably greater amounts of antibiotics than is 